\title{
Physics models in the course "The basics of computer simulation"
}

\author{
Illia O. Teplytskyi ${ }^{1,2}$ \\ ${ }^{1}$ Kryvyi Rih State Pedagogical University, 54 Gagarin Ave., Kryvyi Rih, 50086, Ukraine \\ ${ }^{2}$ Kryvyi Rih Tsentralno-Miska gymnasium of the Kryvyi Rih City Council in Dnipropetrovsk oblast, 16 Pershotravneva \\ Str., Kryvyi Rih, 50000, Ukraine
}

\begin{abstract}
A review of the methodological literature on computer modeling shows the existence of different approaches to its teaching in secondary and higher education. It is a common approach in which the construction of models is carried out using the apparatus of higher mathematics, which is possessed mainly by senior students. This leads to the transfer of the course "Methods of mathematical modeling" for 7-8, and sometimes 9-10 semesters, which reduces its role in shaping the worldview of the future specialist, which takes place in high school and junior high school. This state of affairs forced us to create a propaedeutic course "The basics of computer simulation", which was developed by the joint efforts of the Department of Informatics and Applied Mathematics of Kryvyi Rih State Pedagogical University and the Department of Informatics of the Kryvyi Rih Tsentralno-Miska gymnasium. The methodological support of the course is a textbook designed for high school students and junior high school students.
\end{abstract}

Keywords: physics models, computer simulation

Огляд методичної літератури з комп'ютерного моделювання показує існування різних підходів до його викладання у середній та вищій школі. Загальноприйнятим $є$ підхід, при якому побудова моделей здійснюється з використанням апарату вищої математики, яким володіють переважно студенти старших курсів. Це зумовлює перенесення курсу "Методи математичного моделювання» на 7-8, а іноді і на 9-10 семестри, що знижує його роль у формуванні світогляду майбутнього спеціаліста, яке відбувається у старших класах школи та на молодших курсах вузу.

Такий стан справ змусив вдатися до створення пропедевтичного курсу "Основи комп’ютерного моделювання”, який було розроблено спільними зусиллями кафедри інформатики та прикладної математики Криворізького педуніверситету та кафедри інформатики Центрально-Міської гімназії м. Кривого Рогу. Методичним забезпеченням курсу є навчальний посібник, призначений для учнів старших класів школи та студентів молодших курсів вузу. Концепція курсу та результати його апробації було викладено у працях [2,3].

При створенні посібника однією з основних задач був підбір змістовних моделей, побудова яких не вимагає від учнів знань, що виходять за межі шкільної програми. Основна увага при вивченні моделей приділена технології моделювання. Кожна модель

KMITO 1999: Conference on Computer Simulation and Information Technology in Education, April 19-21, 1999, Kryvyi Rih, Ukraine

๑hs@mg.dp.ua (I. O. Teplytskyi)

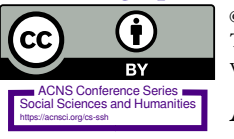

( ) Copyright for this paper by its authors, published by Academy of Cognitive and Natural Sciences (ACNS)

This is an Open Access article distributed under the terms of the Creative Commons License Attribution 4.0 International (CC BY 4.0), which permits unrestricted use, distribution, and reproduction in any medium, provided the original work is properly cited.

ACNS Conference Series: Social Sciences and Humanities 
передбачає не менше трьох версій, що поступово ускладнюються. Робота починається з аналізу досліджуваного предмета (явища), виділення його суттєвих (з точки зору дослідника) якостей, що призводить до висунення певних спрощуючих припущень. Далі, на основі висунутих припущень, відбувається формалізація моделі - запис сформульованих залежностей у вигляді математичних співвідношень. Обчислювальний експеримент - один з основних етапів роботи з побудованою моделлю, який дозволяє, змінюючи іï параметри, отримати уявлення про поведінку досліджуваного об’єкта у різних ситуаціях та зробити певні висновки щодо їі адекватності.

Суттєвим є питання про вибір середовища для моделювання, яке повинне давати можливість відстежувати результати моделювання як у числовій (у вигляді часових рядів), так і у графічній формі (у вигляді графіків залежностей обчислюваних величин). Традиційно таким середовищем є програми, написані однією з мов високого рівня, проте для пропедевтичного курсу, яким $€$ наш, цілком прийнятним середовищем $є$ електронні таблиці, які дозволяють, не відволікаючись на інтерфейс користувача, сконцентруватися безпосередньо на роботі з моделлю.

Чильне місце в обговорюваному курсі посідають динамічні моделі з шкільного курсу фізики, що описуються законами Ньютона. Відомо, що велику кількість динамічних задач засобами елементарної математики аналітично розв'язати неможливо. Проте чисельне розв'язання - методом скінченних різниць - для школярів цілком доступне і не викликає утруднень. Р. Фейнман, піонер використання такого підходу для роботи 3 молодшими студентами, на своїх лекціях використовував саме таблиці, які «є, звичайно, просто зручною формою запису результатів, отриманих з рівнянь, і фактично повністю замінюють їх» [1, p. 170]. Однією з задач, яку він пропонував студентам, був рух планети навколо центрального тіла. Розглянемо ії реалізацію у електронних таблицях.

Нехай наша система складається з чотирьох тіл з масами $m_{0}, m_{1}, m_{2}$ та $m_{3}$ відповідно (figure 1).

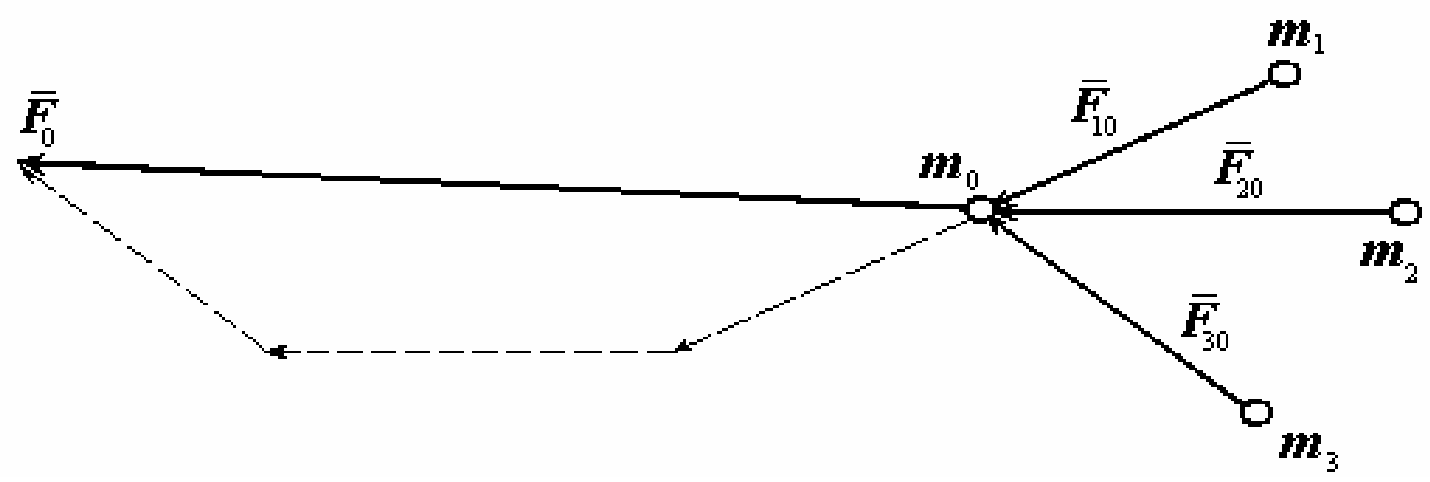

Figure 1: Система чотирьох тіл.

Згідно закону всесвітнього тяжіння, сила, що діє на тіло з масою $m_{i}$ з боку всіх інших, 
дорівнює векторній сумі парних взаємодій:

$$
\boldsymbol{F}_{i}=\sum_{\substack{j \\(i \neq j)}} \boldsymbol{F}_{j i}=\sum_{\substack{j \\(i \neq j)}} G \frac{m_{j} m_{i}}{r_{j i}^{3}} \boldsymbol{r}_{j i}=G m_{i} \sum_{\substack{j \\(i \neq j)}} \frac{m_{j}}{r_{j i}^{3}} \boldsymbol{r}_{j i}
$$

Ця сила, згідно другого закона Ньютона, надає тілу прискорення:

$$
\boldsymbol{F}_{i}=m_{i} \boldsymbol{a}_{i}
$$

Прирівнюючи формули (1) та (2), отримуємо формулу для визначення прискорення:

$$
m_{i} \boldsymbol{a}_{i}=G m_{i} \sum_{\substack{j \\(i \neq j)}} \frac{m_{j}}{r_{j i}^{3}} \boldsymbol{r}_{j i} \Rightarrow \boldsymbol{a}_{i}=G \sum_{\substack{j \\(i \neq j)}} \frac{m_{j}}{r_{j i}^{3}} \boldsymbol{r}_{j i}
$$

Зауважимо, що у нашому випадку ми, взагалі кажучи, не можемо користуватися класичними формулами для визначення швидкості та координати, бо, згідно (3), прискорення залежить від координати, тобто рух тіла під дією сили тяжіння не $\epsilon$ рівноприскореним. Як можна подолати цю перешкоду? Скористаємося чисельним методом - розіб'ємо весь час руху тіла на дуже малі проміжки і будемо вважати, що на кожному з цих елементарних проміжків прискорення є постійним.

Нехай на початку руху $i$-те тіло має координати $\left(x_{i 0}, y_{i 0}\right)$, прискорення $\boldsymbol{a}_{i 0}$ та швидкість $\boldsymbol{v}_{i 0}$. Наприкінці першого проміжку часу тіло набуде прискорення $\boldsymbol{a}_{i 1}$ за (3); його швидкість обчислюватиметься за формулою:

$$
\boldsymbol{v}_{i 1}=\boldsymbol{v}_{i 0}+\boldsymbol{a}_{i 0} \Delta t
$$

Знаючи швидкість, ми можемо обчислити нові координати тіла:

$$
\begin{aligned}
x_{i 1} & =x_{i 0}+v_{i 1 x} \Delta t \\
y_{i 1} & =y_{i 0}+v_{i 1 y} \Delta t
\end{aligned}
$$

Змінюючи $i$, визначаємо прискорення, координати та швидкості всіх інших тіл наприкінці першого проміжку часу. Повторюючи цю процедуру, ми врешті-решт одержимо їх координати, дискретизовані проміжком часу $\Delta t$, що дасть нам змогу побудувати графіки їх руху. Для тестування візьмемо спочатку лише два тіла, а далі вдосконалюватимемо нашу модель, поступово вводячи до розгляду інші тіла.

Отже, ми можемо записати остаточний

\section{АЛГОРИТМ РОБОТИ 3 МОДЕЛЛЮ:}

1. Створимо електронну таблицю за таким зразком: 


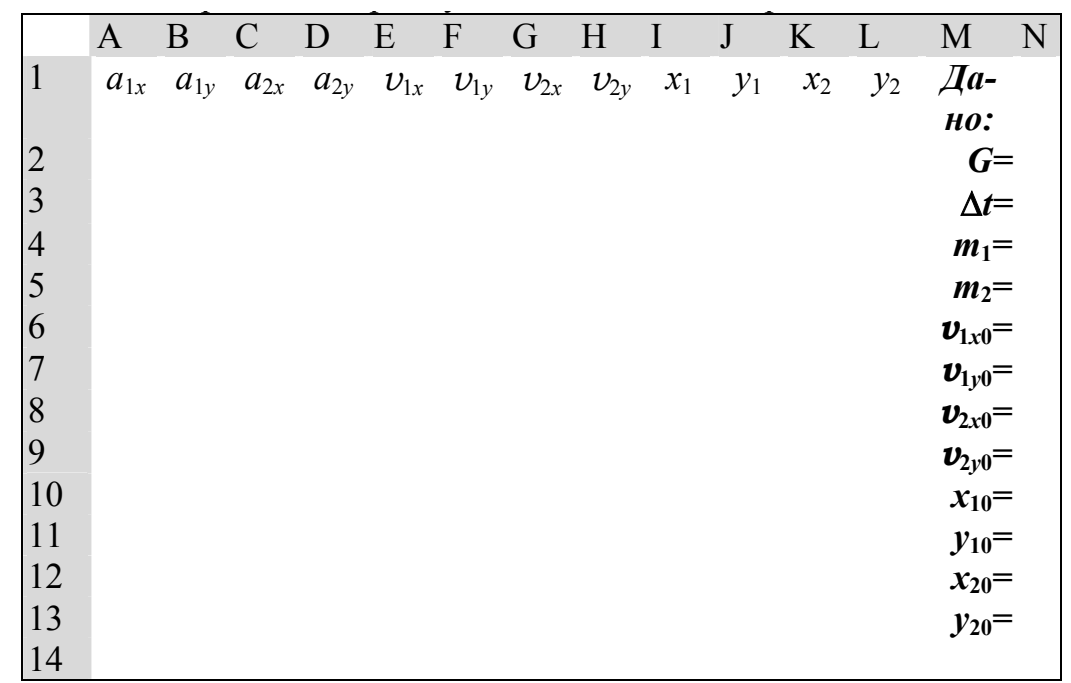

2. Занесемо у другий рядок початкові дані:

\begin{tabular}{|c|c|}
\hline A2 & $=\$ \mathrm{~N} \$ 2^{*} \$ \mathrm{~N} \$ 5^{*}(\mathrm{~K} 2-\mathrm{I} 2) / \mathrm{CTE \Pi EHЬ}\left(\right.$ КОРЕНЬ $\left.\left((\mathrm{K} 2-\mathrm{I} 2)^{\wedge} 2+(\mathrm{L} 2-\mathrm{J} 2)^{\wedge} 2\right) ; 3\right)$ \\
\hline $\mathrm{B} 2$ & $=\$ \mathrm{~N} \$ 2^{*} \$ \mathrm{~N} \$ 5^{*}(\mathrm{~L} 2-\mathrm{J} 2) / \mathrm{CTE \Pi EHb}\left(\mathrm{KOPEHb}\left((\mathrm{K} 2-\mathrm{I} 2)^{\wedge} 2+(\mathrm{L} 2-\mathrm{J} 2)^{\wedge} 2\right) ; 3\right)$ \\
\hline $\mathrm{C} 2$ & $=\$ N \$ 2^{*} \$ N \$ 4^{*}(\mathrm{I} 2-\mathrm{K} 2) / \mathrm{CTE} \Pi E H \mathrm{C}\left(\mathrm{KOPEHb}\left((\mathrm{K} 2-\mathrm{I} 2)^{\wedge} 2+(\mathrm{L} 2-\mathrm{J} 2)^{\wedge} 2\right) ; 3\right)$ \\
\hline D2 & $=\$ \mathrm{~N} \$ 2^{*} \$ \mathrm{~N} \$ 4^{*}(\mathrm{~J} 2-\mathrm{L} 2) / \mathrm{CTE} \Pi \mathrm{CHb}\left(\mathrm{KOPEHb}\left((\mathrm{K} 2-\mathrm{I} 2)^{\wedge} 2+(\mathrm{L} 2-\mathrm{J} 2)^{\wedge} 2\right) ; 3\right)$ \\
\hline E2 & $=\$ \mathrm{~N} \$ 6$ \\
\hline F2 & $=\$ \mathrm{~N} \$ 7$ \\
\hline G2 & $=\$ \mathrm{~N} \$ 8$ \\
\hline $\mathrm{H} 2$ & $=\$ \mathrm{~N} \$ 9$ \\
\hline I 2 & $=\$ \mathrm{~N} \$ 10$ \\
\hline $\mathrm{J} 2$ & $=\$ N \$ 11$ \\
\hline K2 & $=\$ \mathrm{~N} \$ 12$ \\
\hline $\mathrm{L} 2$ & $=\$ \mathrm{~N} \$ 13$ \\
\hline
\end{tabular}

В комірки E2-L2 ми переносимо значення із стовбчика “Дано”, а в A2-D2 заносимо формули для обчислення проєкцій прискорення тіл згідно (3).

3. У третій рядок в комірки A3-D3 скопіюємо вміст комірок A2-D2, а комірки E3-L3 модіфікуємо відповідно до формул (4) та (5):

\begin{tabular}{c|l} 
комірки & формули / числа \\
\hline $\mathrm{E} 3$ & $=\mathrm{E} 2+\mathrm{A} 2^{*} \$ \mathrm{~N} \$ 3$ \\
$\mathrm{~F} 3$ & $=\mathrm{F} 2+\mathrm{B} 2^{*} \$ \mathrm{~N} \$ 3$ \\
$\mathrm{G} 3$ & $=\mathrm{G} 2+\mathrm{C} 2^{*} \$ \mathrm{~N} \$ 3$ \\
$\mathrm{H} 3$ & $=\mathrm{H} 2+\mathrm{D} 2^{*} \$ \mathrm{~N} \$ 3$ \\
$\mathrm{I} 3$ & $=\mathrm{I} 2+\mathrm{E} 3^{*} \$ \mathrm{~N} \$ 3$ \\
$\mathrm{~J} 3$ & $=\mathrm{J} 2+\mathrm{F} 3^{*} \$ \mathrm{~N} \$ 3$ \\
$\mathrm{~K} 3$ & $=\mathrm{K} 2+\mathrm{G} 3^{*} \$ \mathrm{~N} \$ 3$ \\
$\mathrm{~L} 3$ & $=\mathrm{L} 2+\mathrm{H} 3^{*} \$ \mathrm{~N} \$ 3$
\end{tabular}


4. Скопіювати третій рядок у наступні рядки (їх кількість добиратимемо експериментально).

Далі ми можемо розпочати

\section{ОБЧИСЛЮВАЛЬНИЙ ЕКСПЕРИМЕНТ:}

Введемо такі початкові дані: $G=1 ; \Delta t=0,01 ; m_{1}=10 ; m_{2}=8 ; v_{1 x 0}=0 ; v_{1 y 0}=0$; $v_{2 x 0}=2,2 ; v_{2 y 0}=0,1 ; x_{10}=0 ; y_{10}=0 ; x_{20}=1 ; y_{20}=1$ (figure 2). Легко побачити, що їх вибір нічим не зумовлений, проте для тестування моделі цього цілком достатньо. Зауважимо, що при виборі слід звернути увагу на час дискретизації - він не повинен бути занадто великим (при цьому алгоритм, що включає в себе різницеву схему, втратить стійкість - чим більше проміжок, тим менш достовірні результати), проте і занадто малим його робити не слід - нам буде заважати не лише величезна кількість рядків, які нам треба буде скопіювати, а й постійно зростаюча в операціях сумування похибка округлення.

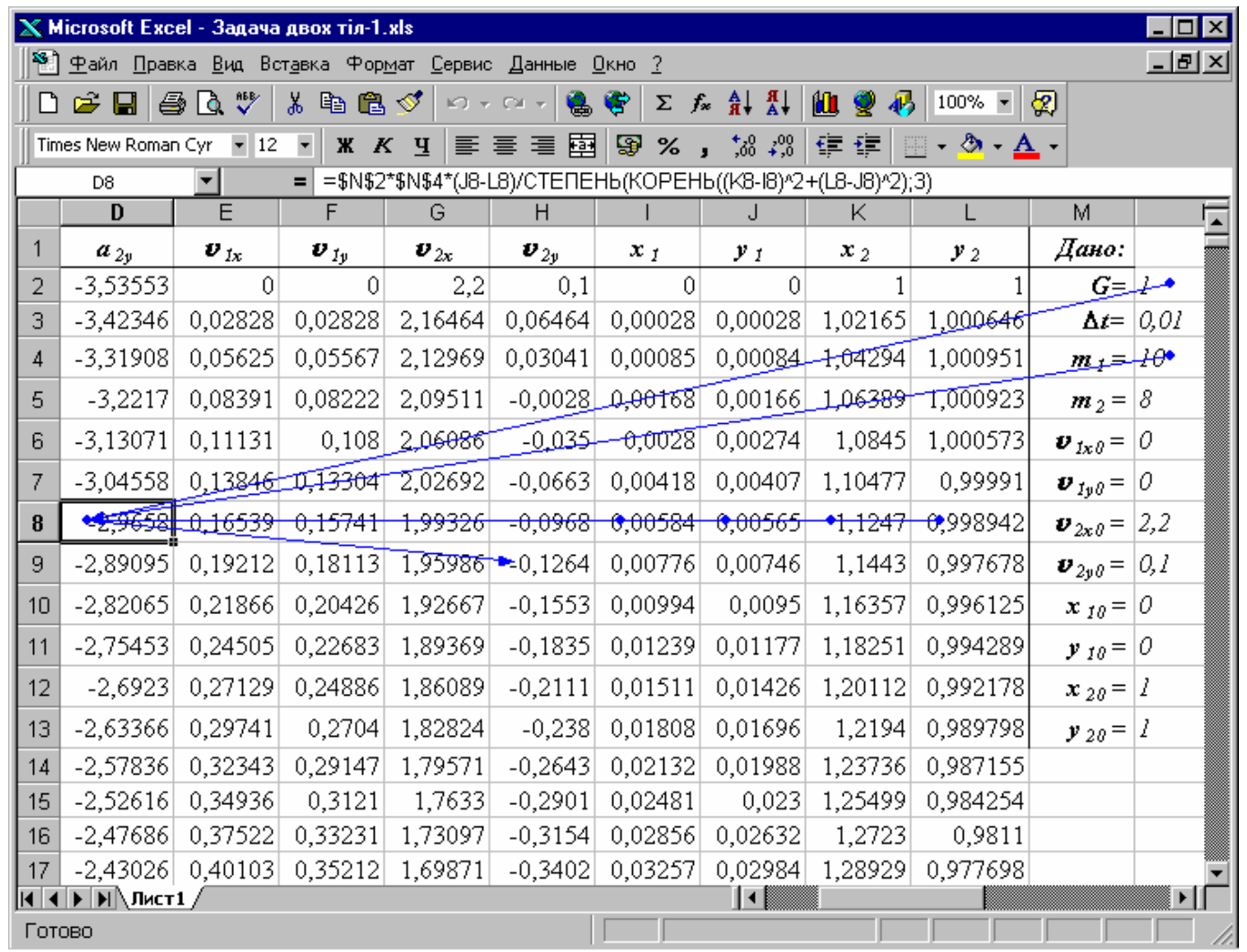

Figure 2: Обчислювальний експеримент.

Ha figure 3 - графік руху тіл, отриманий при введених початкових даних.

Проведемо 


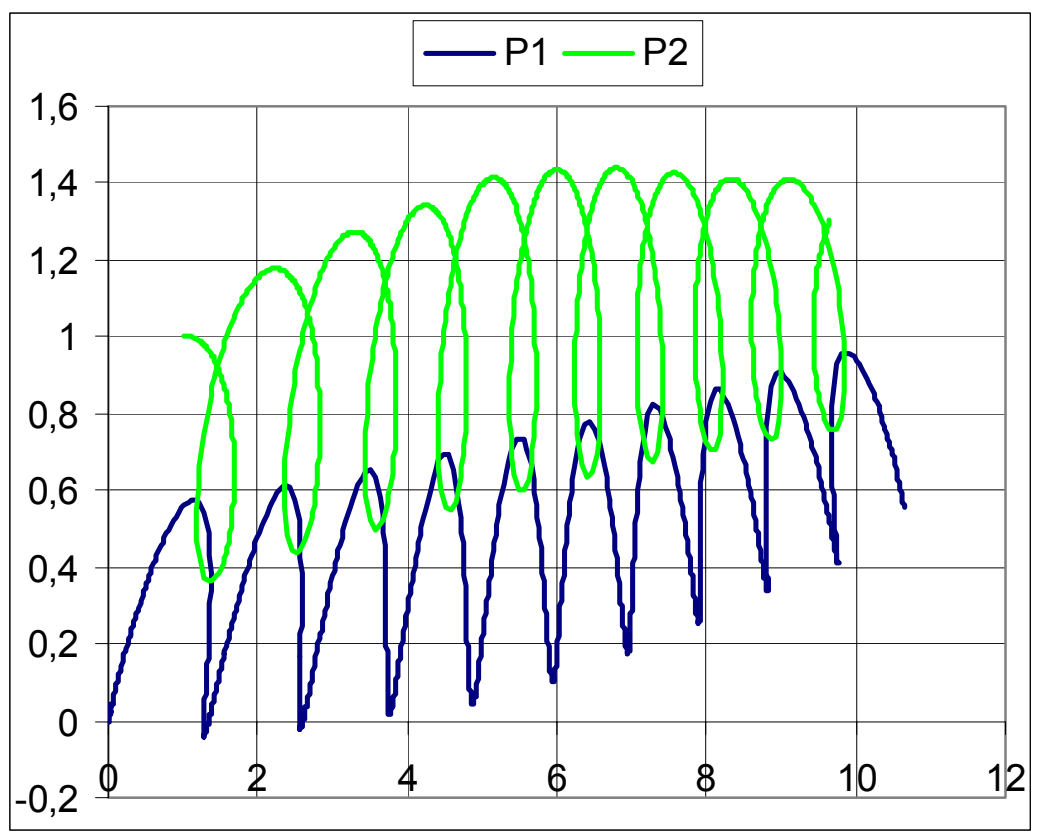

Figure 3: Графік руху тіл за уведених початкових даних.

\section{АНАЛІЗ РЕЗУЛЬТАТІВ ОБЧИСЛЮВАЛЬНОГО ЕКСПЕРИМЕНТУ:}

3 figure 3 видно, що тіла дійсно рухаються згідно закону всесвітнього тяжіння: хоча траєкторія їх спільного руху і звивиста, проте можна побачити, що у моменти зближення прискорення, відповідно до закону всесвітнього тяжіння, збільшується, що, у свою чергу, призводить до різкого збільшення швидкості. Тіла “розлітаються”, але із збільшенням відстані прискорення зменьшується до 0 , аж поки не змінює свій знак. Цей факт означає, що тіла повинні знову зближуватися і т.д.

Поставимо питання:

1. А що буде, якщо тіла занадто зблизяться? Якщо їх маси співрозмірні, то вони на великій швидкості віддалятимуться одне від одного у нескінченність (figure 4a), якщо ж ми маємо справу з системою планета-супутник, то супутник передасть свій імпульс планеті і вирветься з ії «гравітаційних обіймів» (figure 4b).

2. Які початкові умови треба задати, щоб тіла рухались у одному напрямку? Для відповіді на це питання скористаємося законом збереження імпульсу: задамо початкові дані такими, щоб виконувалося, наприклад, співвідношення:

$$
m_{1} v_{1 x 0}=m_{2} v_{2 x 0} .
$$

Результати підтверджують нашу здогадку (figure 5).

Незважаючи на довільність вихідних даних, під час тестування ми впевнилися у якісній відповідності нашої моделі припушенням, покладеним у їі основу (якими у нашому 


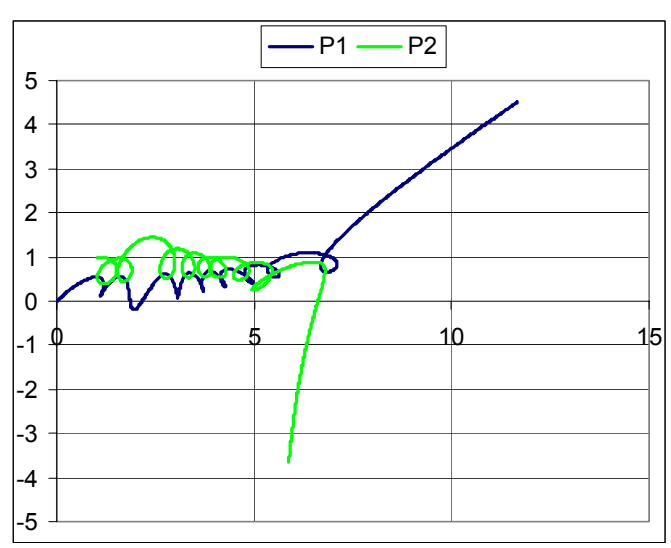

(a)

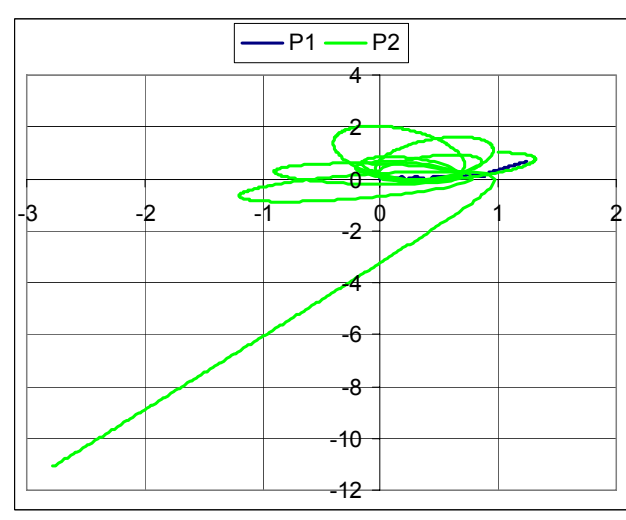

(b)

Figure 4: Моделювання зближення тіл.

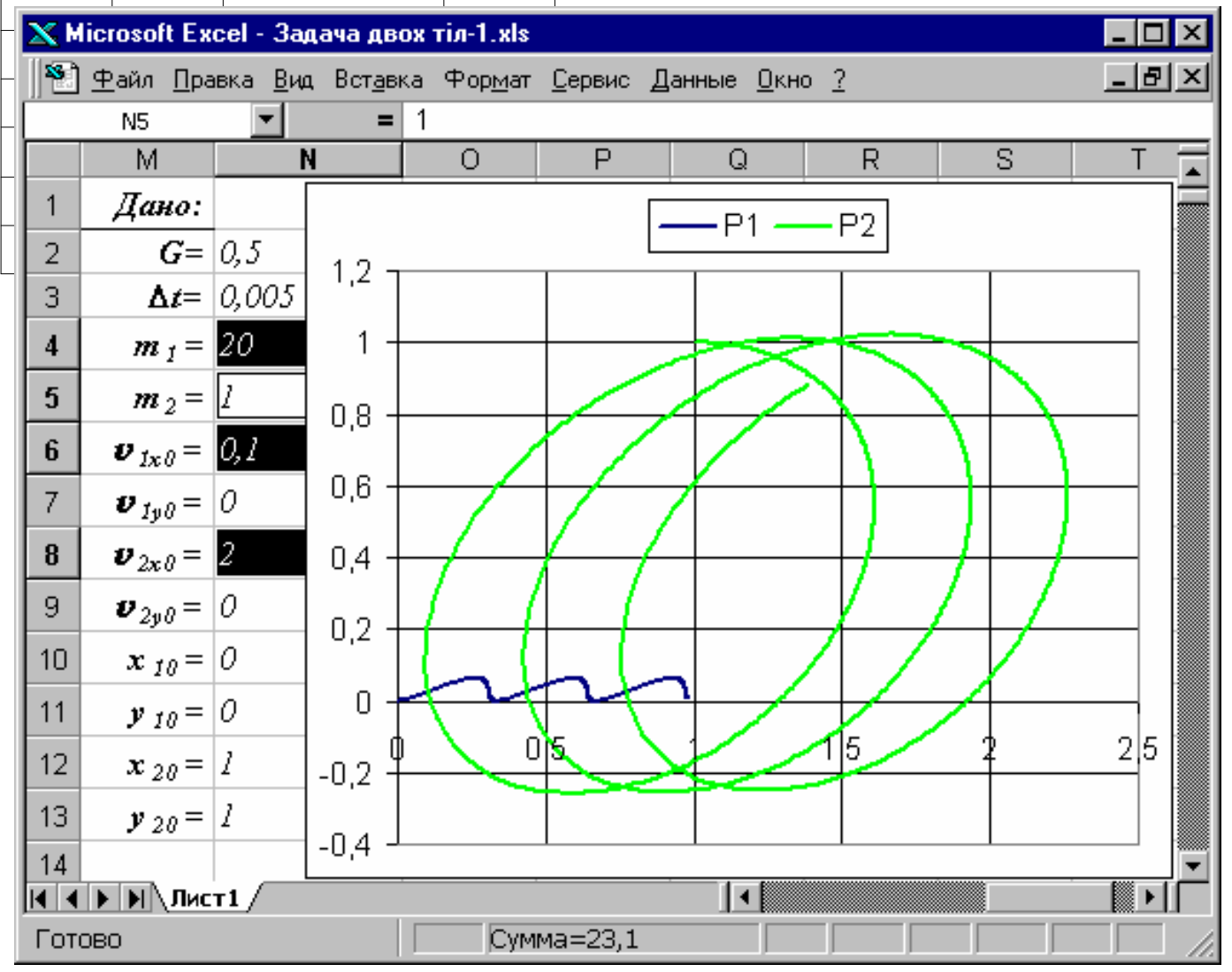

Figure 5: Моделювання руху тіл в одному напрямі. 
випадку виступають закони динаміки). Завдяки використанню зручного середовища для моделювання, у обчислювальному експерименті ми з легкістю змінювали параметри моделі, миттєво отримуючи результати. I, нарешті, наявність зручного засобу візуалізації результатів моделювання дозволило нам провести аналіз експерименту і скорегувати початкові дані у відповідності до тих результатів, які ми хотіли отримати.

\section{References}

[1] Feynman, R.P., Leighton, R.B. and Sands, M.L., 1989. The Feynman lectures on physics, vol. I, Mainly mechanics, radiation, and heat. Redwood City, Calif.: Addison-Wesley. Available from: https://www.feynmanlectures.caltech.edu/I_toc.html.

[2] Soloviev, V.N., Semerikov, S.O. and Teplytskyi, I.O., 1998. Osnovy kompiuternoho modeliuvannia $\mathrm{v}$ serednii shkoli ta pedahohichnomu vuzi [Basics of computer simulation in high school and pedagogical university]. Doprofesiina pidhotovka uchnivskoi molodi $v$ konteksti realizatsii tsilovoi kompleksnoi prohramy "Vchytel”. Dnipropetrovsk, vol. 2, pp.53-56. Available from: http://elibrary.kdpu.edu.ua/handle/0564/683/.

[3] Teplytskyi, I.O. and Semerikov, S.O., 1998. Vyvchennia fraktalnykh klasteriv za dopomohoiu imitatsiinykh kompiuternykh modelei [Study of fractal clusters using simulation computer models]. Zbirnyk naukovykh prats Skhidnoukrainskoho derzhavnoho universytetu. Seriia "Mashynobuduvannia", pp.276-289. Available from: http://elibrary.kdpu.edu.ua/handle/0564/ 695. 